\title{
A further investigation of the correlation between IRT frequency and IRT reinforcement distributions'
}

\author{
J. R. Millenson \\ CARNEGIE INSTITUTE OF TECHNOLOGY
}

\begin{abstract}
Abstraet
Forty sessions of a procedure that yielded a constant rate of reinforcement for lever pressing IRTs of rats over the range $0-25 \mathrm{sec}$. led to a distribution of IRT probabilities over that same range that contained a minimum at about 3-6 sec., and a continuous increase in this probability at longer times. This failure to find a one-to-one correspondence between relative reinforcement rate of IRTs and probability of occurrence of IRTs weakens any explanation of the distribution of the latter based on the distribution of the former.
\end{abstract}

\section{Problem}

The increase in response rate that occurs during initial exposure to variable or random interval reinforcement schedules after CRF (Ferster \& Skinner, 1957; Millenson, 1963) is considered paradoxical because interval schedules in general provide increased probabilities of reinforcement for slow, rather than rapid responding (Anger, 1956; Revusky, 1962). The observed increase in rate under interval contingencies is often described in terms of a distribution of inter-response times (IRTs), whose probabilities of occurrence in time gradually change from an initial time independence to an inverse function of time. Anger (1956) has theorized that such a latter temporal distribution of IRT probabilities can be explained by reference to the relative reinforcement rates associated with different IRT categories that VI produce. In one experiment with VI $5 \mathrm{~min}$, he demonstrated that a rough correlation in the form of the relative reinforcement rates of different IRTs, and IRT probability in time did indeed develop. In a second experiment he showed that a complex procedure that modified the relative reinforcement rates at different IRTs, also correspondingly modified the IRT probability in time (Newman \& Anger, 1954). Anger pointed out that if this correlation between IRT probability in time and IRT relative reinforcement rate was general, a procedure that maintained the latter constant over a given range might also maintain IRT probability constant over the same range. Verification of this suggestion has some interest because a constant IRT probability in time is one of the necessary properties of behavior for an organism to be responding randomly in time (Mueller, 1950). In order to investigate the generality of Anger's correlation and to see whether indeed a random responder might be maintained, rats were exposed to a procedure that appeared likely to generate equal reinforcement rates over a range of IRTs.

\section{Method}

Three hooded rats $(66,67,68)$ lacking prior experimental history were trained to press a lever to obtain a drop of sweetened condensed milk in an apparatus described in detail elsewhere (Millenson \& Hurwitz, 1961). Following training, approximately 750 reinforcements, distributed over 10 daily sessions, were obtained on CRF contingencies. On the following session the rats were exposed to an RI 2 min. schedule (period=4 sec.) for $1 \mathrm{hr}$. On following sessions a procedure known as Interval Selective (IS) reinforcement was in effect.

For the purposes of IS, IRT bands were created. A band consisted of a range of IRTs into which a reinforcement assignment could be selectively made. Thus, following the RI 2 session, a $1 \mathrm{hr}$. session occurred in which three IRT bands were created: 0-10 sec., 10-20 sec., and $>20 \mathrm{sec}$. Reinforcements were assigned randomly in time by the usual RI generator; butby means of an electric roulette wheel, the assignment was delivered at random to only one of the three bands. As a result of this procedure, only when a response occurred terminating an IRT in the particular band to which the assignment had been selectively made, was reinforcement delivered. This procedure insured that over the long run equal numbers of assignments occurred in each band. To attempt to insure that equal numbers of reinforcements would occur in each band a further precaution was taken. When an assignment had been made to a band, no further assignments could be made until the available reinforcement had been claimed. On the following session, the IS bands were 0-7.5 sec., 7.5-15 sec., 15-22.5 sec., and $>22.5 \mathrm{sec}$. This was the last session of preliminary training. On the 40 following hour-long sessions the IS bands were $0-5$, $5-10,10-15,15-20,20-25$, and $>25 \mathrm{sec}$. The RI generator was set to a mean value that kept the total reinforcement rate at the same average value as RI 2 had done, i. e., at about 30 reinforcements per session. On IS this necessitated a mean RI of $15 \mathrm{sec}$.

Animals were maintained on a $22 \mathrm{hr}$. food deprivation rhythm throughout, and run 21-22 hr. deprived.

\section{Results}

The reinforcement assignment system was checked frequently and always found to deliver a close approximation to a rectangular distribution of assignments in the six bands. The procedure maintained behavior throughout the hourly session so that approximately 30 reinforcements were obtained in each session, these being delivered in the irregular order characteristic of VI and RI schedules.

Figure 1 shows the effect on relative frequency of presses in time (filled circles) and probability of IRTs in time (open circles, given as the number of IRTs over the number of opportunities for IRTs of that length or greater, abbreviated IRT/op) emitted at the RI 2 min. session, and then averaged (medians) for sessions 1-5, 21-25, and 36-40 of the IS treatment. In Fig. 1 points are plotted for a category only if $>10$ IRTs were emitted in the category for the RI 2 session; and only if four of the five averaged sessions had $>10$ IRTs in the category. The top plots indicate that for only one animal (68) did the RI 2 procedure itself generate behavior that might be taken as indicating a flat IRT/op curve (one condition 


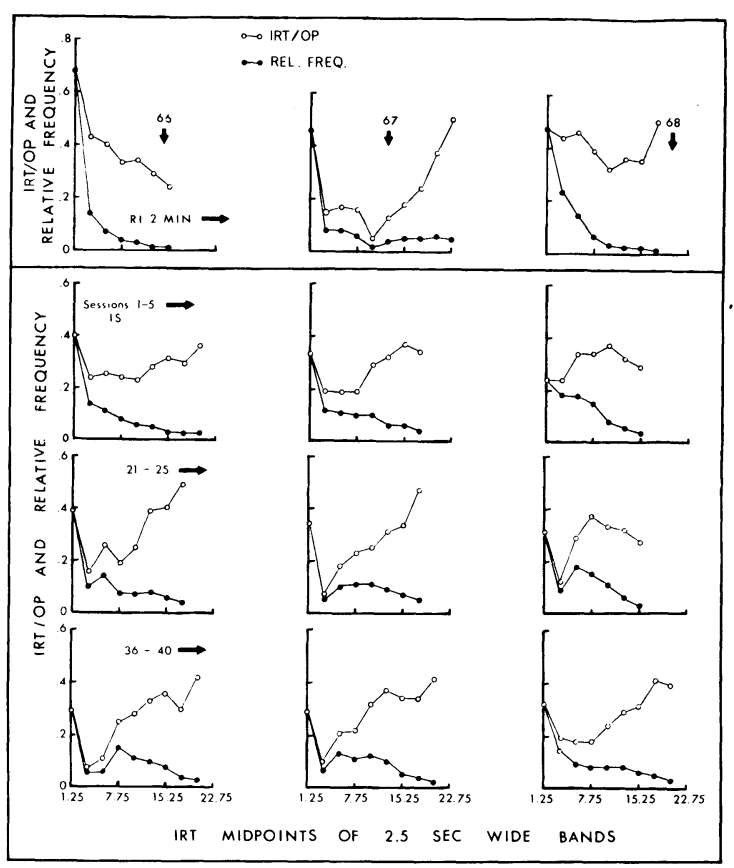

Fig. 1. Distributions of IRTs under RI $2 \mathrm{~min}$. and at different sessions of the IS treatment. Class intervals are $2.5 \mathrm{sec}$. wide.

of a random responder) over a range of IRTs. Rat 66 shows a decline in IRT/op over time usually characteristic of more prolonged exposure to VI. Rat 67 shows a rather atypical IRT/op distribution with a minimum occurring at the $11.25 \mathrm{sec}$. midpoint. On the basis of these RI curves, the IS procedure operated on three rather different initial IRT distributions. Nevertheless its effect as illustrated by the three lowest plots of Fig. 1 appears similar in all cases. By the final five days of the IS treatment, an IRT/op distribution has emerged for all animals that contains a minimum at about 3-6 sec. Longer times are associated with increases in response probability to a maximum value at the longest times where values are still reliable.

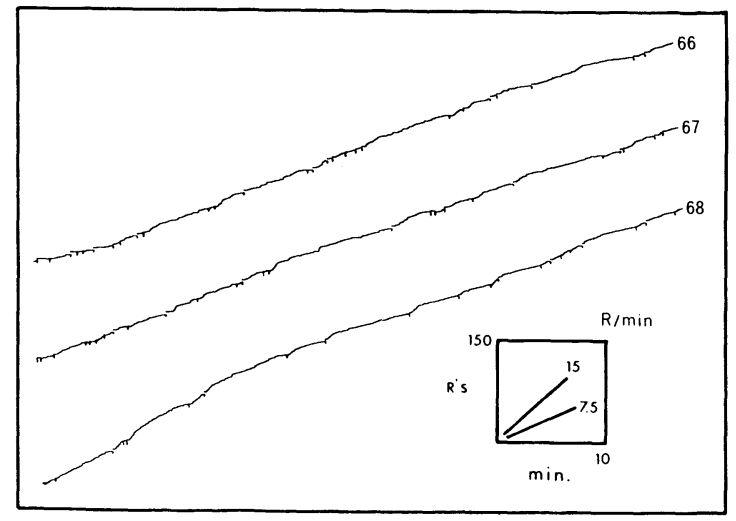

Fig. 2. Pattern of responding at the final session of IS.
IRT/op curves, being averaged over a session or sessions, may not detect any discrimination the animal makes of the schedule by responding differently at different times. The cumulative records of Fig. 2, taken from IS session 40, indicate that some temporal discriminations were formed. Although these records show the irregular reinforcement characteristic of VI and RI, they also reveal negative accelerations between reinforcements, not characteristic of arithmetic VI or RI. In effect, the animals came to sample their IRT bands, beginning with the smallest and working their way gradually through the bands.

\section{Diseussion}

In obtaining his correlation of IRT probability and reinforcement frequency, Anger used an IS procedure that concurrently stored reinforcement assignments in more than one IRT band at a time. Furthermore he added a tandem ratio requirement for short IRTs following their reinforcement assignments to prevent any possible differential strengthening of long-short versus short-short IRT sequences which he showed could happen in certain IS schedules. The present IS procedure differs, therefore, in certain ways from Anger's. Nevertheless it did control reinforcement frequency for different IRTs, and it did not appear to strengthen long-short sequences-a conclusion which can be derived from the negative acceleration of the cumulative records of Fig. 2. Despite this control the IRT/op curves of Fig. 1 differ markedly from those to be expected on the basis of a perfect correspondence with the relative reinforcement of the IRT bands. IS succeeded in giving a uniformly flat curve for reinforcement rate for all bands treated. Nevertheless the final IRT/op result of IS was far from a uniformly flat curve. Thus, however comparable the two IS procedures may be, the present results taken in conjunction with Anger's show that the correlation between reinforcement rate and IRT probability is not an invariant one.

\section{References}

ANGER, D. The dependence of interresponse times upon the relative reinforcement of different interresponse times. J. exp. Psychol., $1956,52,145-161$.

FERSTER, C. B., \& SKINNER, B. F. Schedules of reinforcement. New York: Appleton-Century-Crofts, 1957.

MILLENSON, J. R. Random interval schedules of reinforcement. J.exp. Anal. Beh., 1963, 6, 437-443.

MILLENSON, J. R., \& HURWITZ, H. M. B. Some temporal and sequential properties of behavior during conditioning and extinction. J. exp. Anal. Beh., 1961, 4, 97-106.

MUELLER, C. G. Theoretical relationships among some measures of conditioning. Proc. Nat. Acad. Sci., 1950, 36, 123-130.

NEWMAN, E. B., \& ANGER, E. The effect upon simple animal behavior of different frequencies of reinforcement. Report PLR-33, Office of the Surgeon General, 1954.

REVUSKY, S. Mathematical analysis of the durations of reinforced inter-response times during variable interval reinforcement. Psychometrika, 1962, 27, 307-314.

\section{Note}

1. This research was carried out in the Animal Behavior Laboratory, Birkbeck College, University of London. 